\title{
Alternativas desde América Latina a una modernidad ajena
}

\author{
Alternatives from Latin America to a foreign currency
}

\author{
Jesús Gerardo Salas Gonzales
}

Universidad Nacional Mayor de San Marcos

jsalasgonzales94@gmail.com

\begin{abstract}
América Latina, modernidad y conocimiento. El desarrollo de otro discurso epistémico Mejía Navarrete, Julio

Editorial: Fondo Editorial de la Universidad de la Universidad Nacional Mayor de San Marcos ISBN: 978-99974-77-31-6

Año de edición: 2016
\end{abstract}

Hoy más que nunca cabe rendir homenaje a dos grandes pensadores peruanos, Aníbal Quijano (1928-2018) y José Carlos Mariátegui (1894-1930). Personalidades cuyas ideas enriquecen el pensamiento social peruano y latinoamericano. Críticos del universalismo abstracto y defensores del pensar propio mediante el empleo del "logos y el mito". Legan en sus herederos la apuesta por la fecundidad de ideas, acciones y el desarrollo de una pedagogía transformadora. Y exigen para su cumplimiento el involucrar a la academia y a la sociedad en necesario diálogo horizontal, para ser difusores de la denuncia contra la retórica moderna occidental y la situación de crisis que la misma nos ha generado, así como la propuesta de construcción desde nuestras sociedades del propio devenir.

En esta línea de pensamiento crítico y apuesta transformadora, se encuentra el texto de Mejía, quien, con espíritu docente, sintetiza el saber moderno mediante la explicitación de su raigambre eurocéntrica y su proyecto político de universalización. La modernidad, muy a pesar de los ideales de libertad e igualdad, se sustenta bajo un estado de sumisión y supresión de aquello que no cumple el canon ontológico y epistemológico; establece así un patrón moderno-colonial sobre el cual se sostiene y hace hegemónico el poder occidental europeo.

En sus siete capítulos, el libro plantea una revisión panorámica del eurocentrismo, de los cambios geopolíticos y del saber que lo asentaron. Expone la influencia del pensamiento cartesiano como un hito para la ruptura con el pensamiento teocrático y medieval. Desde el "cogito ergo sum", se le da agencia al individuo, se lo desliga de lo divino y se lo distingue bajo la dualidad razón/sujeto y objeto/naturaleza. Esto tendría dos grandes consecuencias. En primer lugar, resquebrajó la concepción holística del mundo, al separar la naturaleza del hombre y al permitir su explotación sin responsabilidad sobre sus efectos. En segundo lugar, condiciona el cuerpo y todo lo externo a una razón instrumental, cuya fe antropocéntrica partió de la medición 
y el cálculo en pos del interés individual. Sobre este planteamiento, el universalismo cartesiano será delimitado mediante el "yo trascendental" Kantiano, el cual recogiendo la tesis de Aristóteles donde los humanos nacen diferentes, instituye el racismo intelectual, como la relación superior/inferior entre los hombres por razones fenotípicas, ello basado en la idea que la episteme racional moderna está delimitada en un espacio y tiempo concreto: Europa. Hegel complementaría dicha tesis en "Lecciones sobre la filosofía de la historia universal" (1833) donde señala a la historia como la marcha de la razón en el mundo y a Europa como eje y fin de la historia. Estos planteamientos filosóficos portarán legitimidad académica al Eurocentrismo y lo traducen en la "jerarquización social de la modernidad capitalista y colonial" (p.31).

Sería la conquista de América, refiere el autor en los capítulos 2 y 3, el punto de inflexión que unificaría modernidad y colonialidad en lo que desde el pensar crítico se denomina como Colonialidad del Saber. La atribución de la superioridad cultural europea, basada en el uso de la razón, significó la destrucción de formas de pensar nativas, homogeneizando sus trayectorias históricas y culturales bajo la premisa de una marcha evolutiva unidireccional que las situaba en una misma línea de tiempo, universal, con Europa como meta. La consecuencia de ello, no es solo la dependencia política de poblaciones en territorios determinados, sino el control de sus subjetividades, a través de un discurso de identificación con sus conquistadores y con la promesa de modernidad, interiorizada de manera acrítica, al tiempo que se aceptó la ubicación de subordinación conferida por dicho discurso. La tesis del libro plantea que las consecuencias de la conquista, permanecen aún luego de los procesos independentistas, y que históricamente se han evidenciado olas de dominación geopolítica que hacen vigente el discurso moderno-colonial por sobre lo que occidente etiquetó como los "países subdesarrollados" de América Latina y el resto del mundo.

Sin embargo, el discurso moderno alberga contradicciones de facto «...la modernidad a la par que suponía la expansión de la colonialidad, desde su origen recoge la necesidad de una salida emancipadora basada en la igualdad, libertad individual y solidaridad social» (p. 70). Produjo, desde la conquista de América al día de hoy, la documentada y viva prueba de las resistencias, de las epistemes nativas, personajes históricos e intelectuales que plantearon cuestionamientos y alternativas al proyecto eurocéntrico de homogeneización cultural y subordinación geopolítica. El Perú respondió dentro del periodo de la Conquista con Felipe Huamán Poma de Ayala (Bien vivir) y José Gabriel Condorcanqui - Túpac Amaru II (la primera revolución en la historia moderna). Ellos fueron precursores de proyectos políticos independentistas cuestionadores de la racialización y su representación en la estructura política del poder colonial y, en el caso de América Latina, la gesta de la Revolución de Haití que la historia universal omite, pero cuya relevancia no es menor que ser el primer Estado independiente de América y libre desde su población directamente afectada: los esclavos negros. Estos hitos marcaron las resistencias a los regímenes políticos coloniales, fueron punto de partida hacia los debates epistémicos sobre la identidad de estos nuevos sujetos libres y su relación con la matriz eurocéntrica.

Posteriormente, serían los reacomodos geopolíticos producto de la disputa económica de las potencias y sus consecuencias en el mundo, lo que desgastó la legitimidad y hegemonía del patrón moderno-colonial mediante contradicciones cíclicas en coyunturas históricas determinadas. El debate desarrollista post segunda guerra mundial, entre la teoría de la modernización y la teoría cepalina de la dependencia, las crisis de los Estados planificadores (80-90), el mundo unipolar (caída del muro de Berlín y fin de los socialismos realmente existentes) y la globalización del neoliberalismo (Consenso de Washington) dieron en consecuencia la emergencia de las perspectivas pesimistas representadas en los estudios culturales y el posmodernismo mediante el giro hermenéutico. Será en nuestros tiempos que la crítica a la racionalidad eurocéntrica basada en el modelo cartesiano se destacara con

116 | Espiral 1(1): 116 - 118 
las teorías de la complejidad. En esta tarea, fue clave el trabajo de Maturana, sobre la autopoiesis (sistema que se auto produce continuamente), y el trabajo de Quijano, sobre la Heterogeneidad Histórico Estructural.

Mejía señala que esta permanente crítica desde la teoría y la protesta social han permitido aperturar un momento histórico para el pensamiento - acción social latinoamericano y no eurocéntrico, siendo las muestras de pensar propio más relevantes los estudios étnicos, el pensamiento crítico europeo y la teoría de la colonialidad del poder; las cuales recogen la defensa de derechos de género, la lucha contra la discriminación y desigualdad en cualquiera de sus formas y velan por las preocupaciones medioambientales. Estas muestras de imaginación y producción de conocimiento dialogan permanentemente con los movimientos contestatarios que enfrentan a la modernidad y su lógica individualista, depredadora y cosificadora. Estas tensiones deben ser aprovechadas para la transformación de las sociedades con la propuesta de una nueva forma de relacionarse, conocer y construir significados con el mundo.

Finalmente, el objetivo del autor es la apuesta por una episteme particular desde América Latina, que rescate el saber moderno y lo resignifique, desde los saberes locales, en diálogo intercultural. Mejía busca generar el compromiso por un saber ético, social y político, que integre al hombre y la naturaleza, sus relaciones como un todo. Es momento de ir más allá de la razón instrumental, que ha depredado al mundo y lo está llevando a la extinción. Es tiempo de trascender, para dar paso a una razón histórica, donde las clases y las diferencias entre seres humanos pierden toda validez, donde se reconozca su artificialidad y se asuma un rol de equilibrio entre nosotros con la Tierra. Trascender implica dar un salto para superar los basamentos del pensar eurocéntrico y del individualismo cosificador, con el objetivo de constituir una sociedad que, con sensibilidad y empatía, fortalezca el bienestar común desde una perspectiva intercultural.

Julio Mejía Navarrete es miembro de la Cátedra América Latina y la Colonialidad del Poder de la Universidad Ricardo Palma y Docente de la Universidad Nacional Mayor de San Marcos, en Lima. 
118 | Espiral 1(1): 118 - 118 